\title{
A cell lineage analysis of segmentation in the chick embryo
}

\author{
CLAUDIO D. STERN ${ }^{1}$, SCOTT E. FRASER ${ }^{2}$, ROGER J. KEYNES ${ }^{3}$ and DENNIS R. N. PRIMMETT ${ }^{1}$ \\ ${ }^{1}$ Department of Human Anatomy, South Parks Road, Oxford OX1 3QX,UK \\ ${ }^{2}$ Department of Physiology and Biophysics, University of California at Irvine, Irvine, California 92717, USA \\ ${ }^{3}$ Department of Anatomy, Downing Street, Cambridge CB2 3DY, UK
}

\section{Summary}

We have studied the lineage history of the progenitors of the somite mesoderm and of the neural tube in the chick embryo by injecting single cells with the fluorescent tracer, rhodamine-lysine-dextran. We find that, although single cells within the segmental plate give rise to discrete clones in the somites to which they contribute, neither the somites nor their component parts (sclerotome, dermatome, myotome or their rostral and caudal halves) are 'compartments' in the sense defined in insects. Cells in the rostral two thirds or so of the segmental plate contribute only to somite tissue and divide about every $10 \mathrm{~h}$, while those in the caudal portions of this structure contribute both to the somites and to intermediate and lateral plate mesoderm derivatives. In the neural tube, the descendants of individual prospective ventral horn cells remain together within the horn, with a cycle time of $10 \mathrm{~h}$.

We have also investigated the role of the cell division cycle in the formation and subsequent development of somites. A single treatment of 2-day chick embryos with heat shock or a variety of drugs that affect the cell cycle all produce repeated anomalies in the pattern of somites and vertebrae that develop subsequent to the treatment. The interval between anomalies is 6-7 somites (or a multiple of this distance), which corresponds to $10 \mathrm{~h}$. This interval is identical to that measured for the cell division cycle. Given that cell division synchrony is seen in the presomitic mesoderm, we suggest that the cell division cycle plays a role in somite formation.

Finally, we consider the mechanisms responsible for regionalization of derivatives of the somite, and conclude that it is likely that both cell interactions and cell lineage history are important in the determination of cell fates.

Key words: cell lineage, chick embryo, somite mesoderm, neural tube, cell division, segmentation.

\section{Introduction}

In higher vertebrates, segmentation is first apparent with the sequential formation, one pair at a time and in rostrocaudal sequence, of epithelial structures, the somites. Each somite buds off from the rostral end of one of the paired segmental plates. The segmental plate is a rod-like arrangement of loose paraxial mesoderm, situated next to the caudal portions of the neural tube (Fig. 1). At the time of its formation, the somite is an epithelial sphere of tightly apposed cells, which have become polarized during the transition from mesenchymal segmental plate to epithelial somite: the apical surfaces of the cells face inwards into the lumen of the somite, while the entire somite is enveloped by a basal lamina containing fibronectin, laminin and other extracellular matrix molecules (for review see Keynes \& Stern, 1988b). About $10 \mathrm{~h}$ after its formation (by which time about 5-8 more epithelial somites have formed), the somite subdivides into the dermomyotome (which will contribute cells to the dermis of the trunk and to the skeletal musculature) and the sclerotome (which will contribute to the vertebral column and ribs).

It has been known for some time that each sclerotome is divided into a rostral and a caudal portion, but not until more recently that this subdivision determines the pattern of motor axon outgrowth and neural crest migration (Keynes \& Stern, 1984; Rickmann et al. 1985; Bronner-Fraser, 1986; Teillet et al. 1987; Stern \& Bronner-Fraser, 1988). It is also known that the derivatives of somites (vertebrae, dermis and 


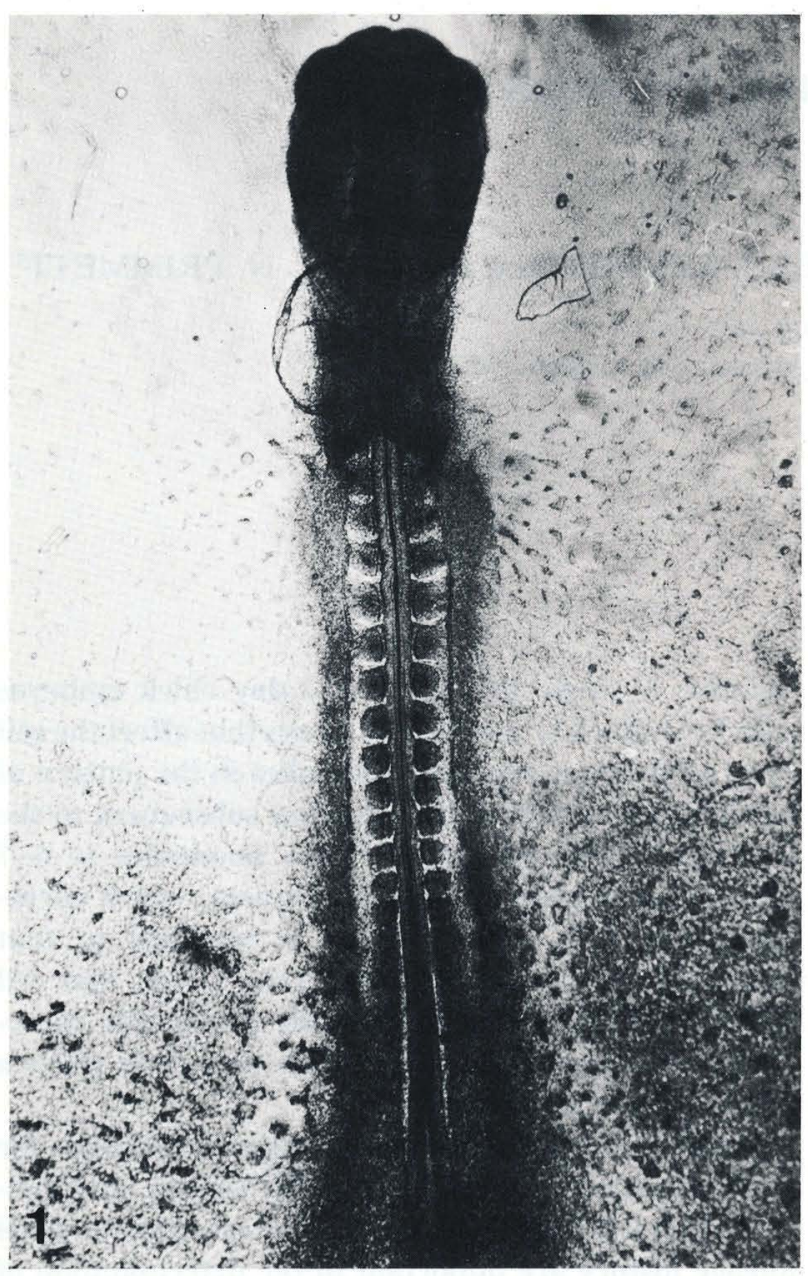

Fig. 1. Whole mount of chick embryo of about 2 days' incubation. The various stages of somite formation can be observed within the one embryo: at the caudal end (bottom of the photograph), the paired segmental plates can be seen. Note that within their most caudal portions they are continuous with the more lateral mesoderm, while at their cranial end they are clearly delimited both medially and laterally. The six or so most caudal somites are still epithelial, while the somites rostral to them have already subdivided into sclerotome and dermomyotome. Note the change in somite shape that accompanies this transition. The length of the embryo at this stage is about $3 \mathrm{~mm}$.

muscle) differ from each other in different embryonic regions. As well as setting up a pattern of repeated elements, therefore, segmentation also requires the correct positioning of the tissue elements derived from the somites.

In order to understand how a segmental pattern is generated, the relationship between the behaviour of single cells and the processes by which the cells are organized into the pattern must be investigated. One important question in this respect is whether cells and their progeny respect spatial boundaries during the development of the segmental pattern. Such a mechanism would simplify the assignment of the elements of a segmental pattern early in development. There is evidence that this is the case during insect segmentation, and the term 'compartment' has been introduced (García-Bellido et al. 1973; Lawrence, 1975; Morata \& Lawrence, 1975; Martínez-Arias \& Lawrence, 1985) to describe the collection of all the surviving progeny of a given group of founder cells (known as a 'polyclone'), which are also confined to a restricted spatial domain in the embryo. All that we know about vertebrate segments in terms of such lineage restrictions is that individual somites are not clones derived from a single founder cell either in the mouse (based on evidence from allophenic animals; Gearhart \& Mintz, 1972) or in the zebrafish (based on single-cell lineage studies at the gastrula stage; Kimmel \& Warga, 1986, 1987, 1988). Neither study has answered the question of whether individual somites, or portions of somites, represent 'developmental compartments' as defined in insects.

Another important question is whether the commitment of cells to various fates during development of the pattern is made in relation to the lineage history of the cells or as a result of interactions with neighbouring tissues. To address this, it is important to establish the time during development at which such specification takes place for a given group of cells. Studies on the zebrafish embryo (Kimmel \& Warga, 1986, 1987, 1988) have revealed a great degree of 'indeterminacy' of cell fates in relation to lineage; it seems that, in this teleost, commitment to particular fates is more strongly dependent upon interactions with other cells than on cell lineage history, and it is important to determine whether this is a general phenomenon in all vertebrate embryos.

The term 'fate' here is used to include the apportionment of cells to specific segments ('regionalization') as well as their commitment to a histologically defined tissue type. This is because vertebrae, muscles and other somite derivatives must differ from each other in different regions of the embryo (these more subtle differences have been termed 'nonequivalence' by Lewis \& Wolpert, 1976). The assignment of cells to specific segments must be intimately linked with the process of segmentation itself, which suggests that, because segmentation in most embryos is a progressive and continuous process, regionalization could be linked to the same timing mechanisms that punctuate the segmental pattern.

In this paper, we have set out to address these questions in the chick embryo. While much previous work has investigated the fate of populations of cells (for example, using the quail/chick chimaera technique or $\left[{ }^{3} \mathrm{H}\right]$ thymidine-labelled grafts), little is known about the fates or developmental potential of 
single cells and their descendants during segmentation in amniote embryos. One major disadvantage of fate mapping by grafting labelled cells or tissues is that the spatial and temporal relationships between cells are necessarily altered. As an alternative, we have analysed the lineage of individual cells in the chick embryo by injecting them with a fluorescent tracer. Using this technique we have been able to investigate the lineage history of somite cells, the development of the component portions of the somite and their derivatives and the lineage history of neural tube cells. We also consider the relationship between segmentation of the neural tube and somite formation, and survey the evidence suggesting that the cell division cycle plays an important part in allocating cells to individual somites.

\section{Cell lineage of somite precursor cells}

We have made use of the fluorescent tracer rhodamine-lysine-dextran to map the lineage of single cells injected at various positions of the segmental plate of the chick embryo. This dye is one of a series of fluorescent lineage tracers, first described by Gimlich \& Braun (1985). These tracers offer many advantages over alternative methods of studying cell lineage: (a) they can be injected into a single, selected cell, (b) they can be immobilized by fixation and survive conventional wax histology, (c) they are large molecules and cannot pass from the injected cell through gap junctions, (d) they are intensely fluorescent, being detectable after at least 11 cell divisions (2000-fold dilution) using a Silicon Intensifier Target (SIT) camera, and (e) they do not appear to be taken up significantly from the extracellular medium, if released there by dead cells (see also Kimmel \& Warga, 1986, 1987, 1988; Wetts \& Fraser, 1988; Wetts et al. 1988). Rhodamine-lysine-dextran is also less phototoxic than its fluorescein counterpart. The results presented in this paper are based on 60 separate injections of presomitic cells in 28 embryos, of which 33 clones were found $48 \mathrm{~h}$ later, in 23 surviving embryos, and are summarized in Figs 2-4.

After injection of a single cell anywhere within the rostral two thirds or so of the segmental plate, we found, two days later, fluorescent cells restricted to somitic tissues. In whole mounts and sections, each fluorescent clone (14 clones recovered) was always discrete, being confined, at most, to a one-segmentlong region within the somite mesoderm. By this time ( $48 \mathrm{~h}$ after injection), the somites at the level of the clone had already differentiated into dermomyotome and sclerotome. Each clone typically consisted of about 30-40 labelled cells, indicating that the injected cell had undergone about five doubling divisions during the $48 \mathrm{~h}$ since the injection, corresponding to a doubling time of about $10 \mathrm{~h}$. The clone did not always correspond exactly to a somite; in many cases it crossed the border into the adjacent somite. It was striking to find that none of the clones examined crossed more than one border: four crossed the boundary between adjacent segments (e.g. Fig. 2A,B), five crossed the intrasegmental border (von Ebner's fissure) (Fig. 2C), and the remaining five clones were confined to a smaller portion of the somite (e.g. Fig. 2D). The clones were also not restricted to either the sclerotome, dermatome or myotome: they sometimes (6 of the 14 clones recovered) included derivatives in two or all three of these tissues (e.g. Fig. 2A-C).

Injection of single cells within the caudal third of the segmental plate (19 clones recovered) also gave rise, 2 days after injection, to discrete clones with characteristics similar to those found after injection of a single cell within the rostral two thirds. The only difference was that clones were more likely (11 of the 19) to include labelled cells within more than one portion (sclerotome, dermatome and myotome) of the somite. As before, none of the 19 clones were found to cross more than one boundary. Unlike the clones derived from injections into a cell in the rostral two thirds of the plate, however, derivatives from these more caudal injections were also found in other mesodermal tissues. This was the case in all but one of the 19 clones. In addition to the fluorescent cells in the somite, labelled cells were found scattered over derivatives of the intermediate mesoderm (mesonephric tubules, Fig. 3A,B) and of the lateral plate mesoderm (including limb bud mesenchyme, blood cells and the endothelium of the floor of the aorta; Fig. $3 \mathrm{C}-\mathrm{H}$ ). While the somitic descendants of the injected cell were rather few in number (also 30-40, as before), the non-somitic descendants added up to a maximum number between 500 and 1500 . It was striking to find that while fluorescent cells were often (11 clones of the 19 recovered) found in the ventral endothelium of the aorta, none were seen in the dorsal endothelium of this blood vessel (roof) (Fig. 3F,G), or in the endothelial lining of any other vessel.

The above results allow us to answer a number of questions regarding the development of somites and other mesodermal tissues in the chick embryo.

\section{(1) Are somites 'developmental compartments'?}

Our results allow us to determine whether a somite, or any of its individual portions, are 'developmental compartments' in the way suggested for the insect epidermal segment (García-Bellido et al. 1973; Lawrence, 1975; Morata \& Lawrence, 1975; MartínezArias \& Lawrence, 1985; see Introduction). The 

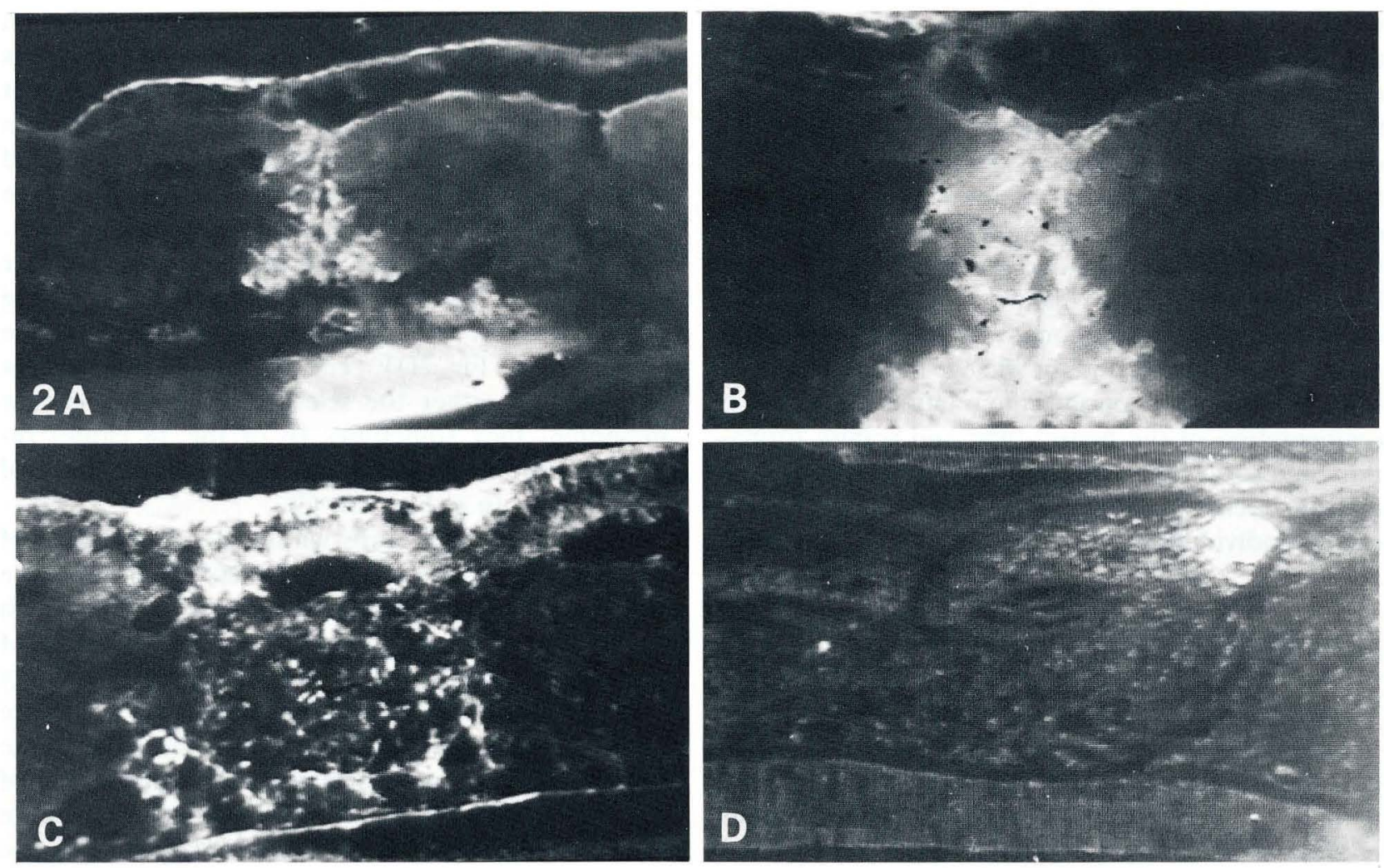

Fig. 2. Single-cell lineage of somite cells. (A) A single cell injected with rhodamine-lysine-dextran in the cranial third of the segmental plate gave rise, two days later, to this clone which spanned two adjacent somites. Fluorescent cells are seen in the sclerotome and dermomyotome. The fluorescence seen in the notochord, below, is artefactual, due to the notochord having lifted off the plane of the slide. (B) Higher power of the region of the border between the two labelled somites shown in A. (C). In this embryo, an injection into the same region gave rise to a clone that spans a whole somite. The labelled cells can be seen scattered in both halves of the sclerotome as well as in the dermomyotome. The ectoderm displays some autofluorescence. (D) Injection of a single cell at the cranial tip of the segmental plate gave rise, in this case, to a very discrete clone confined to a portion of one dermomyotome. No labelled cells were seen in the sclerotome or in any other tissue. In this and other experiments in this paper, injection was done in ovo, into embryos prepared as described elsewhere (e.g. Stern \& Keynes, 1987) through a microelectrode containing tetramethylrhodamine-lysine-dextran as described previously (e.g. Wetts \& Fraser, 1988). After fixation in $4 \%$ paraformaldehyde, embryos were embedded in paraffin wax and sectioned at $10 \mu \mathrm{m}$. They were then viewed by epifluorescence using a Silicon Intensifier Target (SIT) camera and image analyser (Seescan I-3000 system, resolution $256 \times 256$ pixels, 128 grey levels). The photographs are made from averages of eight successive frame captures, directly from the screen of the videomonitor. For each frame stored, a control frame for autofluorescence was also stored, acquired using fluorescein instead of rhodamine filters (e.g. Figs 3D, 5F).

answer, in the case of the somites of the chick embryo, appears to be negative. While clones derived from the injected cell are always confined to a onesegment-long region of somitic mesoderm and never cross more than one boundary within this tissue, they seem just as likely to cross the intersomitic border as the intrasomitic border (von Ebner's fissure). This finding shows that, even within the most cranial portions of the segmental plate, somitic cells give rise to progeny that can cross any boundary (albeit only one). Neither somites nor 'parasegments' are therefore polyclones, because they do not necessarily contain all the surviving descendants of any segmen- tal plate cell, even when the parent cell is labelled shortly before somite formation.

\section{(2) When do somitogenic cells become restricted to a} somitic fate?

Our results also allow us to determine the time during development at which a given mesoderm cell becomes restricted to give rise exclusively to somite tissue. Other experiments (Spratt, 1955; Bellairs, 1963, 1979, 1980; Chernoff \& Hilfer, 1982) suggest that the cranial portions of an isolated segmental plate can form somites, while the more caudal portions cannot. This finding could imply that somitic 
fate is established at some time during the sojourn of a cell in the segmental plate. In agreement with this interpretation, we have found that while a cell injected anywhere within the rostral two thirds of the segmental plate gives rise only to somite derivatives, a cell injected within the caudal one third of the segmental plate can give rise both to somite tissue and to derivatives in the intermediate and lateral plate mesoderm. While this finding is somewhat surprising, it is worth noting that, within its caudal half, the segmental plate of the chick and other vertebrate embryos is continuous with the more lateral mesoderm. This is illustrated by the embryo shown in Fig. 1. Despite its name, therefore, the caudal part of the 'segmental' plate mesoderm contributes cells to the intermediate mesoderm (from which will derive the pronephric and mesonephric systems), and to the lateral plate mesoderm (which gives rise to the lining of the coelom, to the mesenchyme of the limb buds and to many other, non-segmented, tissues within the embryo), as well as to somite tissue.

The segmental plate of the chick embryo contains about 12-13 presumptive somites (see for example, Packard \& Jacobson, 1976). Since somites form every 1.5 h (Menkes et al. 1961), and since segmental plate and somite cells double in number every $10 \mathrm{~h}$ (see below), it follows that the plate contains two cell cycles' worth of somite cells at any one time, and that about 6 somites are produced during each cycle. Despite some mixing of cells within the segmental plate (Stern \& Keynes, 1986; Tam \& Beddington, 1987; see also below), cells at given positions within the plate are arranged in approximate sequence with respect to the time at which they will segment into somites. A cell in the middle of the segmental plate, therefore, will become incorporated into a somite about one cell cycle $(10 \mathrm{~h})$ later. It follows that cells in the caudal third of the plate will remain within the plate for about $15-20 \mathrm{~h}$ before segmenting. These considerations suggest that the divergence of somite and non-somite cells occurs in the caudal portion of the segmental plate two cell cycles, or about $20 \mathrm{~h}$, before visible segmentation.

\section{(3) Rate of cell division of somitic cells}

We can investigate the rate of cell division of somite progenitors at various stages in the development of a somite, simply by counting the labelled cells found after a known period elapsed since the injection $(48 \mathrm{~h})$. We have found that single cells injected within the segmental plate give rise to a clone of about $30-40$ cells in the somite, implying that the doubling time of cells in the segmental plate is of the order of $10 \mathrm{~h}$ (see above). This rate of cell division agrees with that measured for segmental plate and somite cells in a study using $\left[{ }^{3} \mathrm{H}\right]$ thymidine pulse-and-chase followed by autoradiography (Primmett et al. 1989). In the caudal portion of the segmental plate, however, a single injected cell gives rise, in somite tissue, to 30-40 descendants, but also contributes between $500-1500$ cells to other mesodermal tissues. While 30-40 cells represents about 5 doubling divisions $\left(2^{5}=32\right), 500-1500$ cells could be approximated to 10 doubling divisions $\left(2^{10}=1024\right)$. This suggests that, in caudal portions of the segmental plate, the injected cell produces two daughter cells of different developmental fate, which also differ in their rate of cell division: the daughter that will contribute to somite tissues divides once every $10 \mathrm{~h}$, while the one that contributes to non-somite mesoderm divides at twice the rate of its sister, once every $5 \mathrm{~h}$. The presence of fast-dividing cells in caudal regions of the embryo also agrees with the finding that these regions are characterized by high mitotic and labelling indices (Stern \& Bellairs, 1984; Primmett et al. 1989).

\section{Cell lineage in the neural tube}

We have also studied the lineage of cells in the ventrolateral region of the neural tube of the trunk of the chick embryo by injecting single cells with rhodamine-lysine-dextran. $48 \mathrm{~h}$ after injection of single cells (20 separate injections in 19 embryos) at various rostrocaudal levels between the most caudal tip of the forming neural tube and the rostral end of the segmental plate, we found (Fig. 5) that the clone derived from each injected cell, regardless of rostrocaudal level, is always restricted to a region of the spinal cord equivalent to the length of one somite, or, at the most, one and one-half somites. Sometimes it was possible to see labelled motor axons that had been produced by the progeny of the injected cell (e.g. Fig. 5E). As in the somite tissue, the clones produced by a single injected future ventral horn cell, $48 \mathrm{~h}$ after injection, comprised about $30-40$ cells, suggesting that the cell cycle duration of ventral horn progenitor cells is also about $10 \mathrm{~h}$.

While we know that the specificity of motor innervation of somite-derived muscles that invade the limb region does not depend upon the segmental origin of the muscles (Keynes et al. 1987), it remains a possibility that the specificity of motor innervation of the axial muscles does depend on their segmental origin. Our studies may have a bearing on this question, and the issue is being addressed in our laboratories. The possibility that each segment of the ventral horn region of the neural tube might be a 'developmental compartment' remains open (Moody \& Jacobson, 1983). This question cannot be addressed from the present investigations because we do not yet have appropriate markers for the boundaries between adjacent neural tube segments. 


\section{Does the neural tube play a role in somite formation?}

It has been known for some time that the neural tube itself is subdivided into morphological segments, or
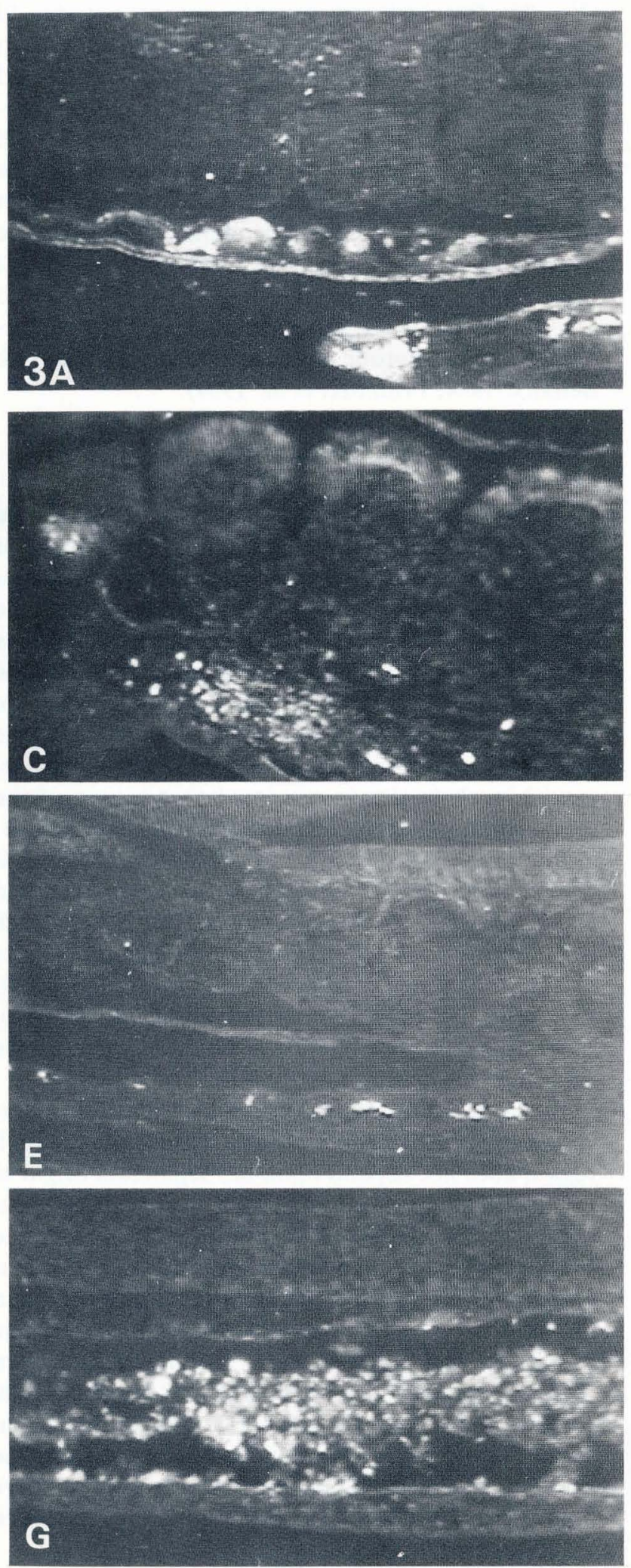

'neuromeres' (von Baer, 1828; Vaage, 1969; Keynes \& Stern, 1985, 1988a). In the larval zebrafish hindbrain, serially repeated clusters of reticulospinal neurones have been described (Metcalfe et al. 1986), which may reflect segmental development within
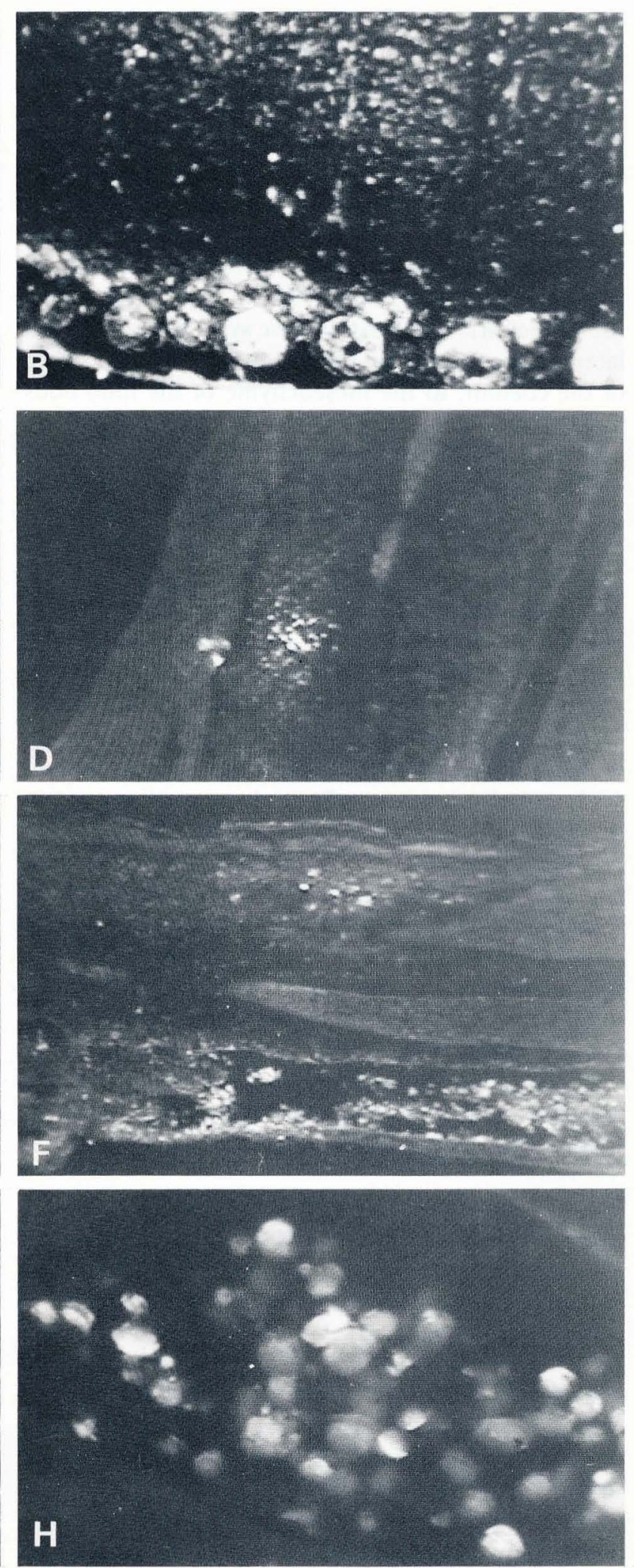
the central nervous system (CNS), and injection of a single cell at the 128-cell stage with a fluorescent lineage tracer gives rise to a periodic pattern of labelled motoneurones in the spinal cord of the larva, with a repeat-period of about (but not exactly) one segment (see Kimmel \& Warga, 1988). Although the function of this subdivision of the CNS is not known in the zebrafish, the chick or any other vertebrate, it is interesting that the length of each neuromere corresponds to the length of a mesodermal segment. Is there an interaction between segments in the CNS and segments in the mesoderm? While most speculations about the functions of neuromeres to date have been concerned with questioning the influences

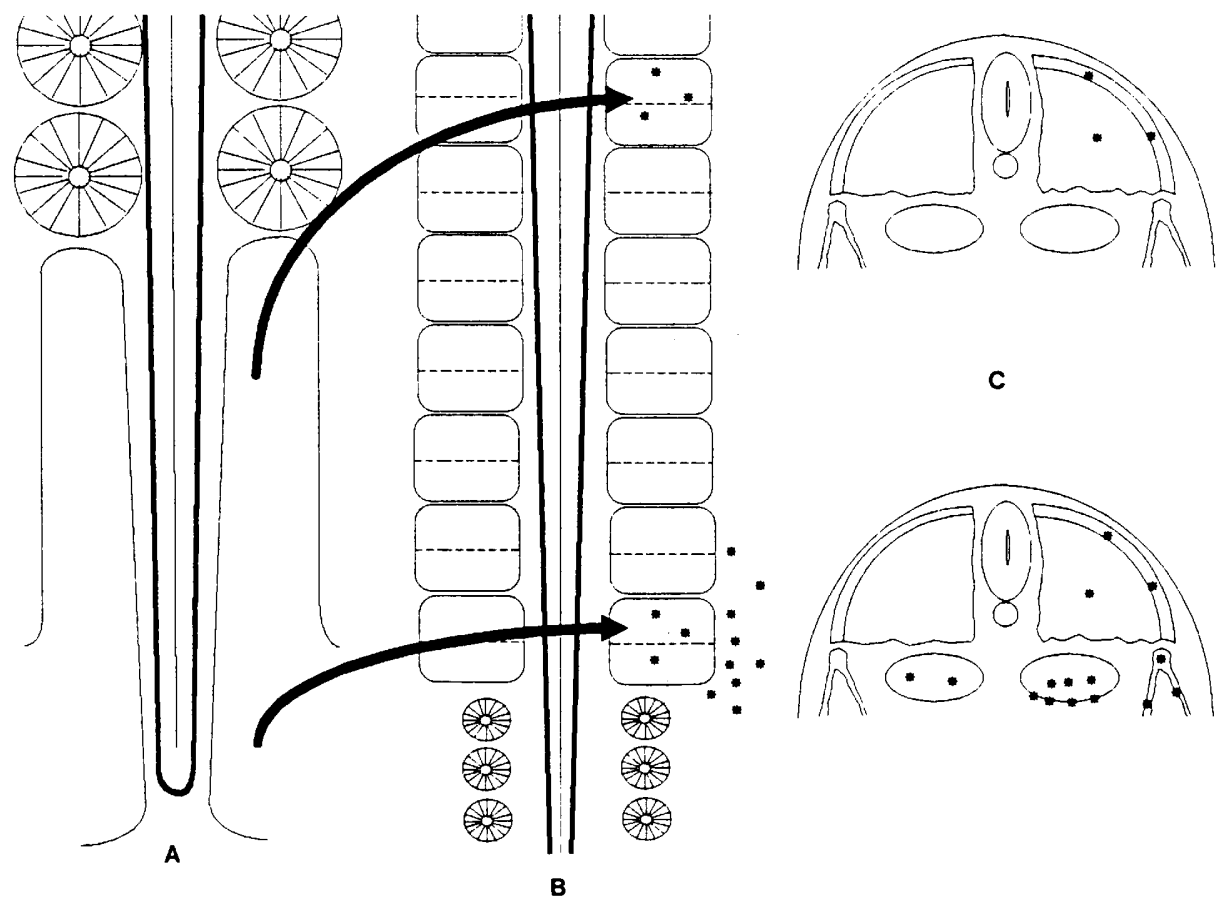

Fig. 4. Summary diagram showing the distribution of the progeny of a single cell injected within the segmental plate of the chick embryo at 2 days' incubation, allowed to develop for a further 2 days after injection. The diagram on the left (A) illustrates the embryo at the time of injection, that in the centre (B) shows the distribution of the progeny of each of the two injections illustrated in $\mathrm{A}$, as viewed in the whole mount $48 \mathrm{~h}$ after injection, and the pair of diagrams on the right (C) show the cells labelled as seen in section. A cell injected in the rostral part of the segmental plate gives rise, two days later, to a clone of 30-40 cells which is restricted, at most, to a one-segment-long region of somitic tissue (cf. Fig. 2). In the caudal portion of the segmental plate, however, the injected cell gives rise to descendants in the intermediate and lateral plate mesoderm, including the floor of the ipsilateral aorta and circulating blood cells, in addition to descendants in the somite (cf. Fig. 3). The somite progeny is distributed like the descendants of a cell injected in the rostral portion of the segmental plate.

Fig. 3. Non-somite descendants of a single cell injected within the caudal third of the segmental plate. (A) In this low-power view of a sagittal section, labelled cells can be seen in some mesonephric tubules (shown in higher power in B) and in some blood cells at the bottom of the photograph. (B) Higher-power view of mesonephric tubules with labelled cells from an adjacent section of the embryo illustrated in A above. Note that many tubules contain a mixture of labelled and unlabelled cells. (C) In this low power view of a sagittal section, labelled cells derived from a single injection can be seen both in the sclerotome of a single somite (top left of the photograph) and spread in the lateral plate opposite several somites. (D) Low power, coronal section. A single injected cell gave rise to progeny within a single sclerotome (towards the centre of the photograph) and to some cells within the hind limb bud mesenchyme. (For control see

Fig. 5F). The labelled cells seen within the limb bud may be somite-derived myoblasts. (E) Sagittal section, showing the spread of cells (derived from a single injection in the caudal segmental plate) within the lateral plate mesoderm. (F) Low-power view, sagittal section. Labelled cells derived from a single injection can be seen scattered through the entire length of a sclerotome (upper part of photograph) as well as in the floor of the aorta and in circulating blood. (G) Higher power view of an adjacent section through the same embryo shown in $\mathrm{F}$ above. Note the presence of labelled cells in the blood and floor of the aorta, and their absence from the roof of this vessel. $(\mathrm{H})$ Higher power view of labelled cells in the blood within a large vessel of an embryo similar to that shown in $\mathrm{F}$ and $\mathrm{G}$ above. While blood cells are somewhat autofluorescent, the difference between labelled and unlabelled cells is clear by the difference in intensity. Under fluorescein filters, all cells display equivalent levels of fluorescence. 

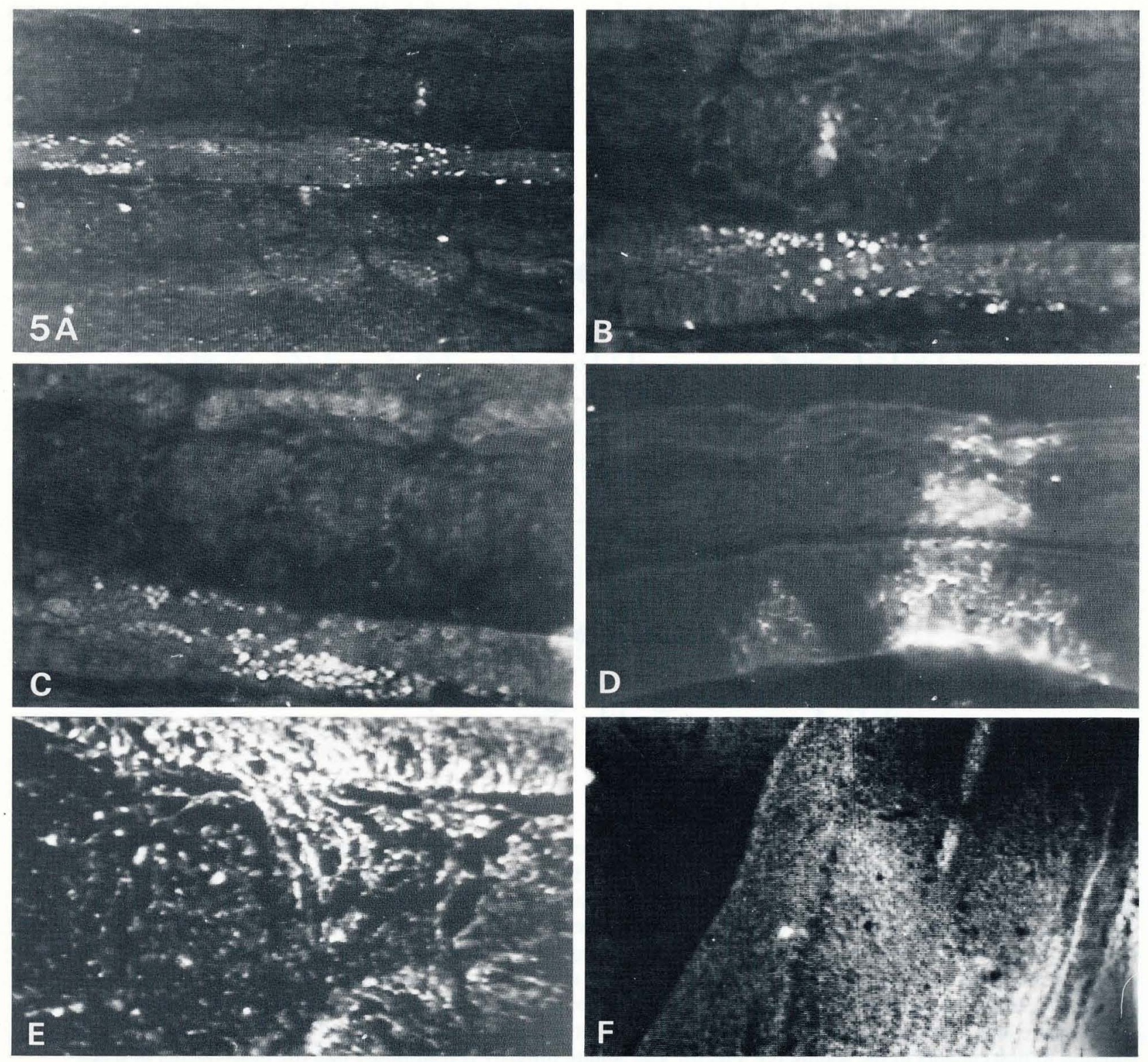

Fig. 5. Labelled progeny resulting from single-cell-injection in the prospective ventral horn region of the neural tube of chick embryos of 2 days' incubation, examined $48 \mathrm{~h}$ later. (A) Coronal section through an embryo which received a separate injection into each of two neural tube cells, 3-somite lengths apart from each other, opposite the middle region of the segmental plate. Each of the two clones has remained discrete and separate, and the clones are still 3-somite lengths apart. The more caudal (right in the picture) injection into the ventral horn was made at the same level as another injection into a segmental plate cell, which gave rise to descendants which are still in register with those derived from the neural tube injection (above, right). (B) Higher power view of the neural tube and sclerotome clones derived from the more caudal injections shown in A. (C) Higher power view of the clone derived from the more rostral injection into the ventral horn of the embryo shown in A. Note that both clones shown in A-C occupy a length equivalent to the rostrocaudal extent of about one somite. (D) Injection into a single neural tube cell and into a segmental plate cell at the same level gave rise to a similar arrangement to that shown in the embryo in A-C above. It is clear that the cells in the somite are not neural crest cells because (i) they cross the border between the two adjacent somites, (ii) most of the cells are within the caudal half of the sclerotome and (iii) some of the cells are seen within the dermomyotome. Note the presence of some fluorescence to the left (rostral) of the main part of the neural tube clone. These could be axons; in adjacent sections, continuity was seen between these and the major portion (more caudal) of the clone. (E) An example of labelled motor axons, derived from a single cell injected in the ventral horn, seen here entering the rostral sclerotome (below in the photograph). (F) Control image, viewed under fluorescein optics, of the same section shown in Fig. 3D. Note that, while the whole section still autofluoresces slightly, the rhodamine-labelled cells are not visible. 
by the somite mesoderm on neuromeres (see Keynes \& Stern, 1985, 1988a), the possibility that neuromeres may have an influence on somite tissue has barely been considered.

There is apparently conflicting information on the question of whether the neural tube is important in segmentation of the mesoderm. On the one hand, Bellairs (1963) and others have found that somite formation can proceed from segmental plate mesoderm even after extirpation of the neural tube. On the other hand, other authors, such as Teillet \& Le Douarin (1983) have reported that removal of the neural tube and notochord from the trunk of a chick embryo caused the neighbouring somite mesoderm to lose its segmental organization, while Fraser (1960) found that a neural tube implanted into the normally unsegmented lateral plate mesoderm can elicit the segmentation of this tissue. It is also clear that while the segmental plate mesoderm in the trunk undergoes segmentation to produce somites, the paraxial mesoderm of the head (which occupies an equivalent position to the segmental plate in cranial regions) does not. The difference in behaviour between these two tissues could be determined by influences from the neural tube in each region, although this has not yet been tested experimentally.

It is possible, therefore, that the neural tube imparts segmental information to the neighbouring mesenchyme. For example, those cells derived from progenitors at the caudal end of the segmental plate that find themselves next to the neural tube proceed to give rise to the more obviously segmented tissues (somites), while those that are far from the influence of the tube give rise to unsegmented structures (blood, aortic endothelium and mesenchyme of other organs).

The patterns of expression of vertebrate homeobox genes (reviewed recently by Stern \& Keynes, 1988) may have a bearing on this question. It is clear that all of the 25 or so mouse homeobox genes that have been studied to date are expressed in discrete regions of the neural tube. However, with the possible exception of Hox 1.5 (Gaunt et al. 1986), the boundaries of expression of homeobox genes do not appear to correspond precisely to the boundaries between neuromeres (Keynes \& Stern, 1988b; Stern \& Keynes, 1988). If functional parallels with Drosophila can be drawn, then, the vertebrate patterns of expression correspond more closely to those of the 'gap' or 'selector/homeotic' genes than to the 'pair-rule' or 'segment polarity' genes, which are expressed in a more obviously segmented (i.e. periodic) fashion (Nüsslein-Volhard \& Wieschaus, 1980). Given the current degree of interest in both segmentation and homeobox genes, we have little doubt that further study will throw light on this issue in the near future.

\section{Evidence for direct involvement of the cell cycle in segmentation}

Recently, we reported that a single brief heat shock, given to chick embryos during the second day of development, can generate repeated anomalies in the somites that develop after the shock, which are separated from each other by a distance of 6-7 unaffected somites or a multiple of this interval (Primmett et al. 1988) (Fig. 6). The anomalies consist of small, fused or abnormally large somites, which later give rise to malformations of the axial skeleton (fused neural arches, ectopic or fused ribs, and other anomalies). We argued that, because each somite takes about $1.5 \mathrm{~h}$ to form, a 6 - to 7 -somite interval corresponds to about $10 \mathrm{~h}$, and predicted that this might be the duration of the cell cycle in somitic cells.

In a subsequent study, using $\left[{ }^{3} \mathrm{H}\right]$ thymidine pulseand-chase followed by autoradiography (Primmett $e t$ al. 1989), we confirmed this value for the cell cycle duration of chick embryo somitic tissue. We also showed that a single brief treatment with each of a variety of drugs that interfere with the cell cycle causes repeated somite anomalies similar to those seen after heat shock.

From these results, we suggested that these treatments all act in a similar way on somite formation: they appear to alter the number of cells that become recruited into each forming somite. This implies that segmental plate cells destined to segment together are apportioned with respect to their position within the same cell division cycle. If this finding is correct, we might expect that cells destined to form each somite should be relatively synchronous with each other at the time of segmentation.

\section{Evidence of cell division synchrony during somite development}

The mitotic and ${ }^{3} \mathrm{H}$-TdR-labelling indices of the segmental plate of the chick embryo display a pattern of regions of high index separated from each other by regions, about six prospective somites long, of lower index (Stern \& Bellairs, 1984; Primmett et al. 1989) (Fig. 7). Because presumptive somite cells within the segmental plate appear to be arranged in order of developmental age, those destined to form somites sooner being located more rostrally, it can be inferred from these results that cells destined to form the same somite are relatively synchronous with one another over the range of at least two cell division cycles prior to segmentation, which is the extent of the segmental plate (12-13 somites).

The synchrony of somite cells does not end at the time of somite formation. Further bursts of labelled and mitotic cells can be seen more rostrally, in somite regions (Primmett et al. 1989). It is therefore poss- 


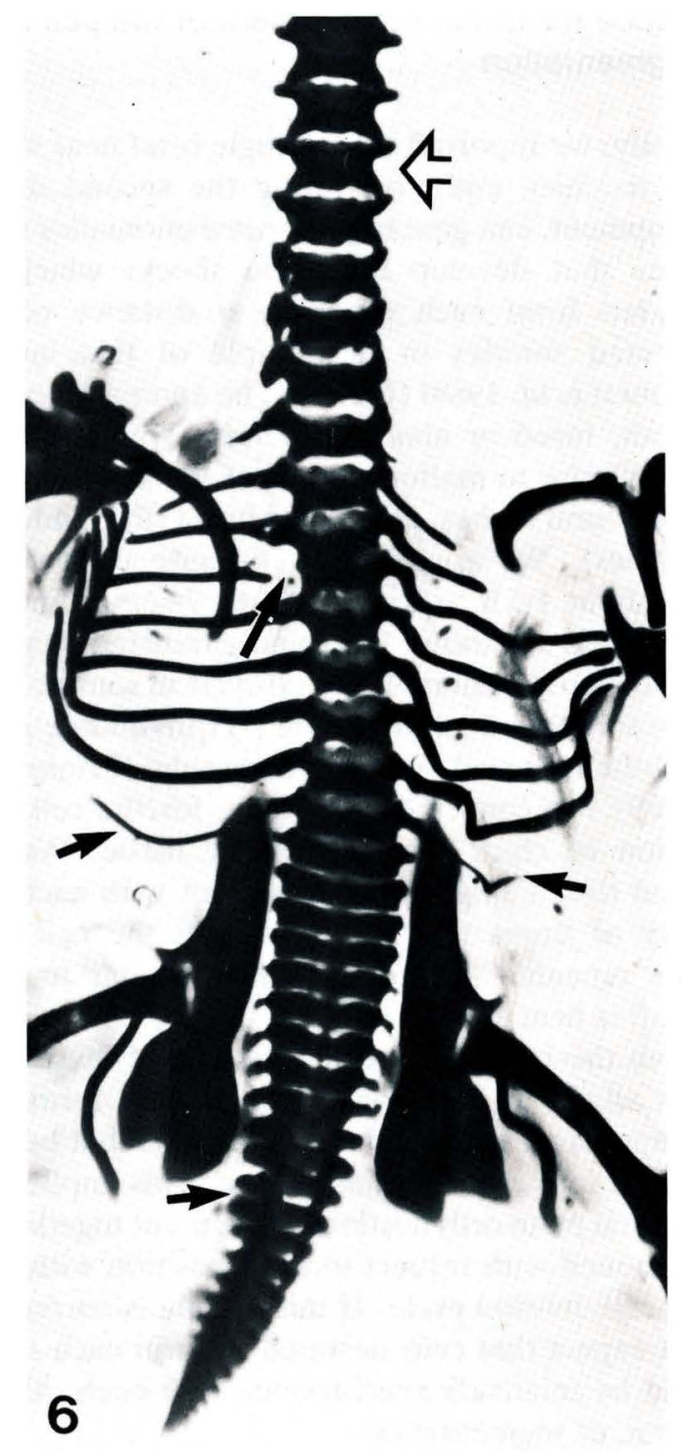

Fig. 6. Skeleton of an embryo treated with a single heat shock of $55^{\circ} \mathrm{C}$ for $52 \mathrm{~min}$ on the second day of development and allowed to develop for 7 days after the shock. Three separate anomalies can be seen (solid arrows): a vertebral fusion with an associated detached rib at cervical level 16 to thoracic level 1 (C16-T1), an ectopic lumbar rib at L1, and a malformed neural arch in the third caudal vertebra. The open arrow shows the level of the last somite formed at the time of the shock. The first (most rostral) anomaly is found 7 segments caudal to that last formed at the time of the shock, the second anomaly lies 6 segments caudal to the first, and the third anomaly seen is $13(=6+7)$ segments caudal to the second. Stained with Alcian blue as a whole mount to visualize the cartilaginous skeleton. From Primmett et al. (1988).

ible that certain stages of somite formation and of their subsequent development can be correlated with specific mitotic events in the life of the somitic cells (Fig. 8): two cell division cycles before segmentation, cells are in the caudal portion of the segmental plate, and at this time they may diverge from non-somitic mesoderm cells (see above); by one cell cycle before segmentation, they are located around the middle portions of the segmental plate, and they undergo a last mitotic division at around the time of segmentation. One complete cell division cycle later, the somites differentiate into dermomyotome and sclerotome.

These observations suggest that the cell cycle itself plays a role in somite formation and in their subsequent development in the chick embryo.

If the cells of the chick segmental plate are mixed experimentally, they nevertheless are able to contribute to the formation of a normal pattern of somites, which segment at the normal rate (Menkes \& Sandor, 1969) and which even have the normal rostral-caudal sclerotome composition (Stern \& Keynes, unpublished observations), within only $2 \mathrm{~h}$ of the operation. One interpretation of this result is that cells destined to form particular somites, or portions of a somite, are able to sort out if mixed experimentally.

We could therefore speculate that presomitic cells in the paraxial mesoderm of the chick and other amniotes possess a cellular 'clock', linked to the cell division cycle, which allows them to behave in a cellautonomous manner until close to the time of segmentation. Shortly before somite formation the cells destined to segment together might increase their adhesion to one another (Bellairs et al. 1978; Cheney $\&$ Lash, 1984), which would allow them to sort out from their non-segmenting neighbours in the plate.

\section{Regional specification during chick segmentation}

Having discussed the lineage history of somite precursor cells in the chick embryo and the mechanisms that might control the timing of segmentation, it remains for us to consider the mechanisms that might determine the fate of the diverse derivatives of the somite, and to discuss whether these developmental decisions are made with respect to the lineage history of the cells concerned or as a result of cell interactions. Three processes will be addressed: the establishment of rostrocaudal differences within the sclerotome, the commitment to become dermomyotome or sclerotome, and the acquisition of regional characteristics in later derivatives of the somite (the vertebral column, the dermis and the skeletal musculature).

\section{(1) Rostral/caudal determination}

If either half of a newly formed somite is excised and transplanted into any other site in the embryo, it always gives rise to sclerotome with the properties of 


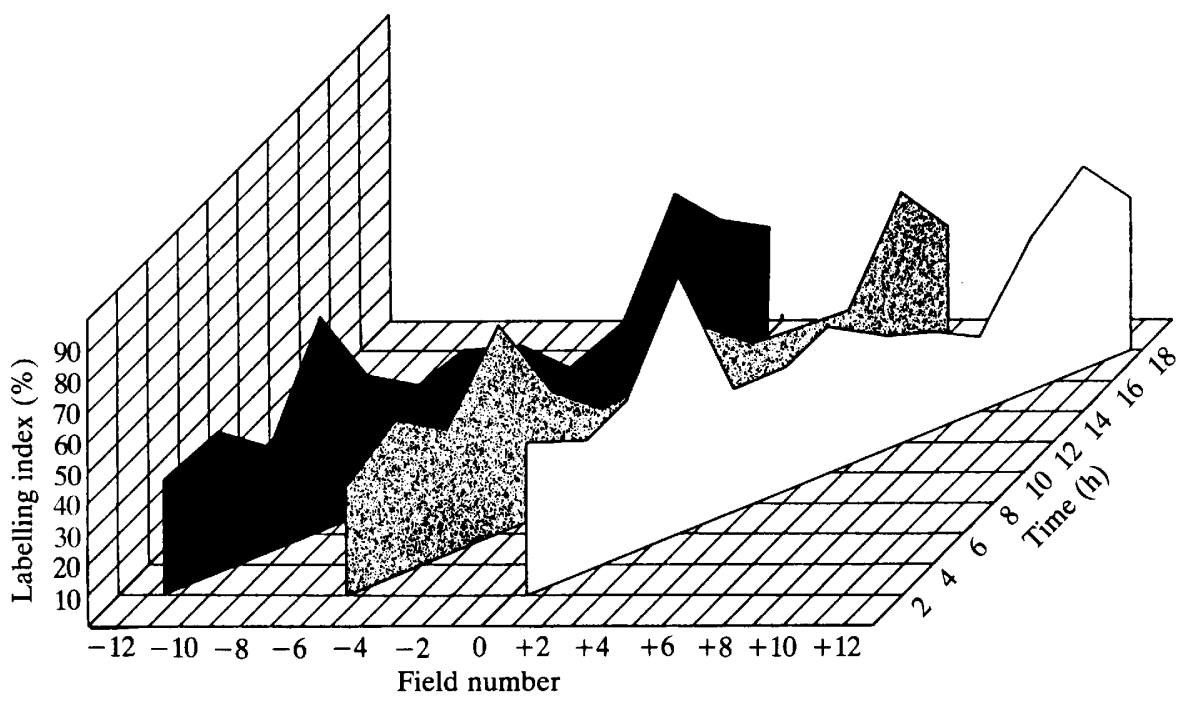

Fig. 7. A three-dimensional plot of position in the segmental plate and somites (X-axis, where 'field' represents a microscope field of $100 \mu \mathrm{m} \times 100 \mu \mathrm{m}$, relative to ' 0 ', corresponding to the rostral end of the segmental plate; negative numbers are caudal to this position, while positive field numbers correspond to somite numbers) against, in the Z-axis, time of chase in $\mathrm{h}$ after a single pulse of $\left[{ }^{3} \mathrm{H}\right]$ thymidine at time 0 , and the labelling index (\% labelled cells; $\mathrm{Y}$-axis). Note the peaks, corresponding to a large proportion of labelled cells. This plot reveals synchrony of cells within the segmental plate and somites of the chick embryo at two days' incubation. From Primmett et al. (1989).

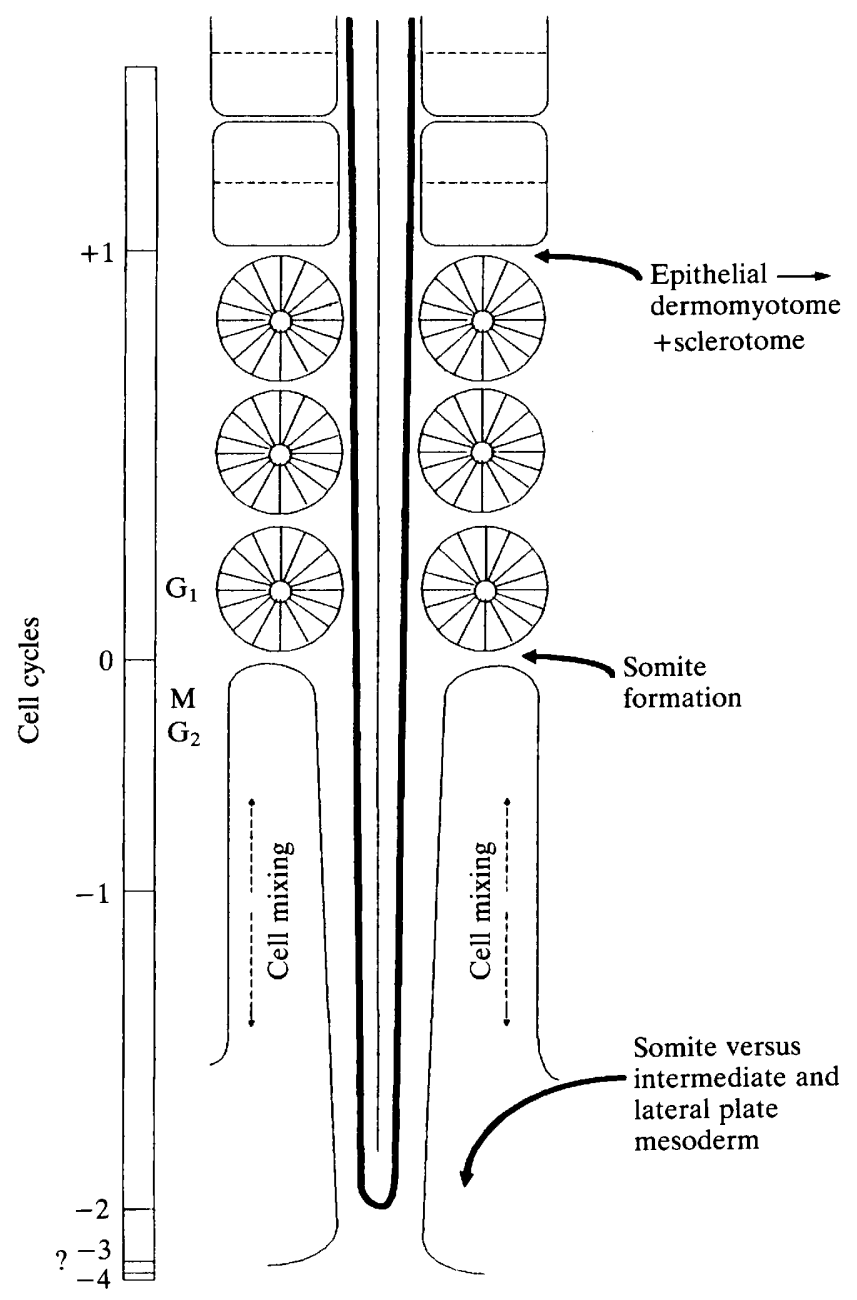

the half of origin, irrespective of the position into which it is grafted (Stern \& Keynes, 1987). This rules out the possibility that the rostrocaudal fate of somite cells is determined after the time of overt somite formation from the segmental plate. Rather, it seems likely from a variety of considerations discussed in detail elsewhere (Stern \& Keynes, 1986; Primmett et al. 1988) that the rostrocaudal decision is made during somite formation, perhaps in relation to the length of time each cell spends adjacent to the developing segment border. One interesting consequence of this is that, since the determination of the rostral half of a newly forming somite as rostral would

Fig. 8. Diagram illustrating, in idealized form, the relationship between the cell division cycle and events during somite formation in the chick embryo. Somite formation is taken to occur at ' 0 ' on a cell cycle scale shown on the left of the diagram. Cells injected with a lineage tracer two cell cycles before this time (represented by -2 in the diagram) contribute descendants both to the somites and to non-somite mesoderm. In the middle of the segmental plate there may be some cell mixing. One cell division cycle after segmentation $(+1$ in the diagram), the somite subdivides into dermomyotome and sclerotome. Although the interval between ' 0 ' and ' +1 ' is shown as three somites in the diagram, it corresponds to 5-8 epithelial somites in the embryo. Because a peak of high mitotic index is often seen at the rostral end of the segmental plate (Stern \& Bellairs, 1984; Primmett et al. 1989), it is assumed that the most recently formed somite contains a preponderance of its cells in the $G_{1}$ phase of the cell division cycle. 
coincide with that of the caudal half of the preceding somite as caudal, rostrocaudal determination would be parasegmental, as has been suggested for the epidermal segments of Drosophila (Martínez-Arias \& Lawrence, 1985). If this is the case, rostrocaudal determination would be an example of a developmental decision made in relation to cell interactions, rather than the lineage history of the cells. This conclusion is consistent with our results from the cell lineage analysis of somite precursors: except that when cells are injected at the rostralmost tip of the segmental plate, just prior to somite formation, the derivatives of the injected cells are not necessarily confined to either half of the sclerotome.

\section{(2) Specification of sclerotome and dermomyotome}

The dorsoventral polarity of the somites forming from the cranial tip of the segmental plate can still be reversed by inverting them about their dorsoventral axis (Gallera, 1966; Jacob et al. 1974). This finding indicates that somite cells are specified as dermomyotome or sclerotome close to the time of somite formation, but before subdivision, which occurs $8-10$ h (equivalent to $6-8$ somites, or one complete cell division cycle) later. The commitment for dermomyotome and sclerotome probably depends, therefore, upon interactions with the adjacent epiblast and endoderm rather than on the lineage history of the cells. Again, this conclusion is consistent with the results of our cell lineage analysis: clones were not usually found to be restricted to any of the three components derived from the somite. In those cases in which the progeny of the injected cell gave rise exclusively to one component, it is possible that an extreme dorsal or extreme ventral cell had been injected, and its progeny never moved sufficiently about the dorsoventral thickness of the segmental plate to become affected by the layer with which it did not come into contact.

The divergence of sclerotome and dermomyotome may not, however, be as irreversible as the above discussion suggests. Indeed, there is some evidence (for review see Hall, 1978) that the neural tube and/or notochord can elicit vertebral chondrogenesis from any portion of the somite, be it sclerotome or dermomyotome, even after apparent differentiation of these two components. It is possible, therefore, that the specification of dermomyotome and sclerotome begins around the time of somite formation, but that dynamic interactions with neighbouring structures maintain and/or modulate their subsequent differentiation.

\section{(3) Regionalization of the vertebral column, dermis and muscle}

Vertebrae in different regions of the vertebral column are morphologically different from one another, suggesting that individual somites have defined regional identities. At what stage are somite cells determined to form particular skeletal elements? When thoracic segmental plate mesoderm is grafted into the cervical region, ribs develop in the neck (Kieny et al. 1972). The same is true for the plumage pattern in the trunk, which is derived from the dermatomes (Mauger, 1972). The muscle pattern in the limb, on the other hand, does not behave in this way: non-wing-level somites, when transplanted to the wing region, give rise to normal wing muscles (Chevallier et al. 1977) and are innervated appropriately for their new position (Keynes et al. 1987). These results might be interpreted to mean that skeletal and dermal derivatives of the somite are regionally determined in the segmental plate or earlier, while the voluntary muscles of the limb become determined much later.

However, the possibility that regional specification for dermis and sclerotome does not take place until later cannot be ruled out from these experiments. Transplantation experiments resulting in unaltered fate cannot be interpreted to mean that specification has already occurred at the time of the operation. For example, it is possible that the transplanted cells behave autonomously within the plate, being unable to take positional cues from their new surroundings after the operation. In other words, it is possible that cells do not 'know' that they have been transplanted, although their fate has not yet become sealed irreversibly at the time of the transplant. Clearly, these transplantation experiments do not help us to determine when regional specification occurs.

Because somite pairs form sequentially, specification as cervical, thoracic, etc. could be linked to the time of formation of each somite pair. Our heatshock and other experiments (Primmett et al. 1988, 1989) suggest that somite progenitor cells have an internal 'clock' that makes them segment at a particular time. The experiments suggest that this clock is linked directly to the cell division cycle. It is possible that regional specification for sclerotome, dermal and axial muscle derivatives of the somite could also be linked to this clock. If this is the case, this would be an example of a lineage-related decision. On the other hand, the presumptive limb muscle cells can become any muscle and be innervated by any motor nerve until they enter the limb, $24 \mathrm{~h}$ or more after the corresponding dermomyotomes form. The commitment to form a particular muscle, therefore, is an example of a developmental decision influenced by cell interactions, as myoblasts would need to interpret positional cues from the rest of the limb. 


\section{Conclusions}

Our results show that, although single cells within the segmental plate give rise to discrete clones in the somites to which they contribute descendants, neither the somites nor any of their component parts can be considered to be 'compartments' in the sense defined in insects. Cells in the rostral two thirds or so of the segmental plate contribute only to somite tissue and divide about every $10 \mathrm{~h}$, while those in the caudal portions of this structure contribute both to the somites and to intermediate and lateral plate mesoderm derivatives, and divide at twice that rate. In the trunk neural tube, the progeny of individual prospective ventral horn cells remains discrete within the horn.

We have also considered the evidence suggesting that there is a degree of cell division synchrony among those segmental plate cells that will segment together, and we suggest that segmentation can proceed in a relatively cell-autonomous manner. We also propose that the cell division cycle plays an important role in the control of somite formation.

Finally, we give consideration to the mechanisms responsible for regionalization of derivatives of the somite, and conclude that it is likely that both cell interactions and cell lineage history are important in the determination of cell fates.

The investigations reported in this paper were supported by a project grant from the Medical Research Council to C.D.S. and R.J.K. The single-cell injections were made possible by a McKnight Scholar Award, NSF grant BNS86/08356 and a gift from the Monsanto Corporation to S.E.F., and a travel grant from the Wellcome Trust to C.D.S. The Wellcome Trust also provided the funds, in the form of a grant to C.D.S., for the purchase of the equipment used for the analysis of the clones. Thanks are also due to Dr Patrick Tam for his comments on the manuscript. We are also indebted to Marianne BronnerFraser for putting up with us during the injection experiments while expanding her own lineage.

\section{References}

Bellairs, R. (1963). The development of somites in the chick embryo. J. Embryol. exp. Morph. 11, 697-714.

Bellairs, R. (1979). The mechanism of somite segmentation in the chick embryo. J. Embryol. exp. Morph. 51, 227-243.

Bellairs, R. (1980). The segmentation of somites in the chick embryo. Boll. Zool. 47, 245-252.

Bellairs, R., Curtis, A. S. G. \& Sanders, E. J. (1978). Cell adhesiveness and embryonic differentiation. $J$. Embryol. exp. Morph. 46, 207-213.

Bronner-Fraser, M. (1986). Analysis of the early stages of trunk neural crest cell migration in avian embryos using monoclonal antibody HNK-1. Devl Biol. 115, $44-55$.

Cheney, C. M. \& Lash, J. W. (1984). An increase in cell-cell adhesion in the chick segmental plate results in a meristic pattern. J. Embryol. exp. Morph. 79, $1-10$.

Chernoff, E. A. G. \& Hilfer, S. R. (1982). Calcium dependence and contraction in somite formation. Tiss. Cell 14, 435-450.

Chevallier, A., Kieny, M. \& Mauger, A. (1977). Limb-somite relationships: origin of the limb musculature. J. Embryol. exp. Morph. 41, 245-258.

FRASER, R. C. (1960). Somitogenesis in the chick. III. The role of induction. J. exp. Zool. 145, 151-167.

Gallera, J. (1966). Mise en évidence du rôle de l'ectoblaste dans la différenciation des somites chez les oiseaux. Rev. Suisse Zool. 73, 492-503.

García-Bellido, A., Ripoll, P. \& Morata, G. (1973). Developmental compartmentalisation of the wing disk of Drosophila. Nature, New Biology 245, 251-253.

Gaunt, S. J., Miller, J. R., Powell, D. J. \& Duboule, D. (1986). Homeobox gene expression in mouse embryos varies with position by the primitive streak stage. Nature, Lond. 324, 662-664.

Gearhart, J. D. \& Mintz, B. (1972). Clonal origins of somites and their muscle derivatives: evidence from allophenic mice. Devl Biol. 29, 27-37.

GimLich, R. L. \& BRAUN, J. (1985). Improved fluorescent compounds for tracing cell lineage. Devl Biol. 109, 509-514.

Hall, B. K. (1978). Developmental and Skeletal Biology. London: Academic Press.

JАСOB, H. J., Christ, B. \& JАСов, M. (1974). Die Somitogenese beim Hühnerembryo. Experimente zur Lageentwicklung des Myotom. Verh. Anat. Ges. 68, 581-589.

Keynes, R. J. \& Stern, C. D. (1984). Segmentation in the vertebrate nervous system. Nature, Lond. 310, 786-789.

Keynes, R. J. \& Stern, C. D. (1985). Segmentation and neural development. Trends Neurosci. 8, 220-223.

Keynes, R. J. \& Stern, C. D. (1988a). Neural segmentation in vertebrates. In The Making of the Nervous System (ed. J. G. Parnavelas, C. D. Stern \& R. V. Stirling), pp. 84-100. Oxford: Oxford University Press.

Keynes, R. J. \& Stern, C. D. (1988b). Mechanisms of vertebrate segmentation. Development 103, 413-429.

Keynes, R. J., Stirling, R. V., Stern, C. D. \& Summerbell, D. (1987). The specificity of motor innervation of the chick wing does not depend upon the segmental origin of muscles. Development 99, 565-575.

Kieny, M., Mauger, A. \& Sengel, P. (1972). Early regionalization of the somitic mesoderm as studied by the development of the axial skeleton of the chick embryo. Devl Biol. 28, 142-161.

Kimmel, C. B. \& Warga, R. M. (1986). Tissue-specific cell lineages originate in the gastrula of the zebrafish. Science 231, 365-368.

Kimmel, C. B. \& WARGA, R. M. (1987). Cell lineages 
generating axial muscle in the zebrafish embryo. Nature, Lond. 327, 234-237.

Kimmel, C. B. \& Warga, R. M. (1988). Cell lineage and developmental potential of cells in the zebrafish embryo. Trends Genet. 4, 68-74.

LAWrence, P. A. (1975). The structure and properties of a compartment border: the intersegmental boundary in Oncopeltus. In Cell Patterning. Ciba Fdn. Symposium 29, pp. 3-23.

LeWIS, J. H. \& WolPert, L. (1976). The principle of non-equivalence in development. J. theor. Biol. 62, $479-490$.

Martínez-Arias, A. \& Lawrence, P. A. (1985). Parasegments and compartments in the Drosophila embryo. Nature, Lond. 313, 639-642.

Mauger, A. (1972). Rôle du mésoderme somitique dans le développement du plumage dorsal chez l'embryon de poulet. II. Régionalisation du mésoderme plumigène. J. Embryol. exp. Morph. 28, 343-366.

Menkes, B., Miclea, C., Elias, S. \& Deleanu, M. (1961). Researches on the formation of axial organs. I. Studies on the differentiation of the somites. Stud. Cercet. Stiint. Med. 8, 7-33.

Menkes, B. \& SANDor, S. (1969). Researches on the development of axial organs. Rev. Roum. Embryol. Cytol. 6, 65-88.

Metcalfe, W. K., Mendelson, B. \& Kimmel, C. B. (1986). Segmental homologies among reticulospinal neurons in the hindbrain of the zebrafish larva. $J$. comp. Neurol. 251, 147-159.

Moody, S. A. \& Jacobson, M. (1983). Compartmental relationships between anuran primary spinal motoneurons and the somitic muscle fibers that they first innervate. J. Neurosci. 3, 1670-1682.

Morata, G. \& Lawrence, P. A. (1975). Control of compartment development by the engrailed gene in Drosophila. Nature, Lond. 255, 614-616.

Nüsslein-Volhard, C. \& Wieschaus, E. (1980). Mutations affecting segment number and polarity in Drosophila. Nature, Lond. 287, 795-801.

Packard, D. S. \& Jacobson, A. G. (1976). The influence of axial structures on chick somite formation. $\mathrm{Devl}$ Biol. 53, 36-48.

Primmett, D. R. N., Stern, C. D. \& Keynes, R. J. (1988). Heat shock causes repeated segmental anomalies in the chick embryo. Development (in press).

Primmett, D. R. N., Norris, W. E., Carlson, G. J., Keynes, R. J. \& Stern, C. D. (1989). Periodic segmental anomalies induced by heat-shock in the chick embryo are associated with the cell cycle. Development (in press).

Rickmann, M., Fawcett, J. W. \& Keynes, R. J. (1985). The migration of neural crest cells and the growth of motor axons through the rostral half of the chick somite. J. Embryol. exp. Morph. 90, 437-455.

SpratT, N. T. JR (1955). Analysis of the organizer center in the early chick embryo. I. Localization of prospective notochord and somite cells. J. exp. Zool. 128, $121-164$.

Stern, C. D. \& Bellairs, R. (1984). Mitotic activity during somite segmentation in the chick embryo. Anat. Embryol. 169, 97-102.

Stern, C. D. \& Bronner-Fraser, M. (1988). The role of the surrounding tissues in the migration and differentiation of neural crest cells in the trunk of the chick embryo. (in preparation).

Stern, C. D. \& Keynes, R. J. (1986). Cell lineage and the formation and maintenance of half-somites. In Somites in Developing Embryos (ed. R. Bellairs, D. A. Ede \& J. W. Lash), pp. 147-159. New York: Plenum Press.

Stern, C. D. \& Keynes, R. J. (1987). Interactions between somite cells: the formation and maintenance of segment boundaries in the chick embryo. Development 99, 261-272.

Stern, C. D. \& Keynes, R. J. (1988). Spatial patterns of homeobox gene expression in the developing mammalian central nervous system. Trends Neurosci. 11, 190-192.

TAm, P. P. L. \& Beddington, R. S. P. (1987). The formation of mesodermal tissues in the mouse embryo during gastrulation and early organogenesis. Development 99, 109-126.

Teillet, M.-A. \& Le Douarin, N. M. (1983). Consequences of neural tube and notochord excision on the development of the peripheral nervous system in the chick embryo. Devl Biol. 98, 192-211.

Teillet, M.-A., Kalcheim, C. \& Le Douarin, N. M. (1987). Formation of the dorsal root ganglion in the avian embryo: segmental origin and migratory behavior of neural crest progenitor cells. Devl Biol. 120, 329-347.

VAAGE, S. (1969). The segmentation of the primitive neural tube in chick embryos (Gallus domesticus). Adv. Anat. Embryol. Cell Biol. 41 (3), 1-88.

VON BAER, K. E. (1828). Über die Entwicklungsgeschichte der Thiere. Königsberg.

Wetts, R. \& Fraser, S. E. (1988). Multipotent precursors can give rise to all major cell types of the frog retina. Science 239, 1142-1145.

Wetts, R., O'Rourke, N. A. \& Fraser, S. E. (1988). Vital-dye analyses of neural development and connectivity. In The Making of the Nervous System (ed. J. G. Parnavelas, C. D. Stern \& R. V. Stirling), pp. 52-69. Oxford: Oxford University Press. 